Revista lus et Praxis, Año 17, No 2, 2011, pp. 537 - 550

ISSN 0717 - 2877

Universidad de Talca - Facultad de Ciencias Jurídicas y Sociales

"Anef con SII:

¿libertad sindical, debido proceso o libertades públicas?"

Fernando Muñoz León

\title{
ANEF CON SII: ¿LIBERTAD SINDICAL, DEBIDO PROCESO O LIBERTADES PÚBLICAS?
}

FERNANDO MUÑOZ LEÓN ${ }^{1}$

El derecho, al decir de la teoría de sistemas, consiste en una esfera comunicativa que, sometiendo todos los fenómenos a su código legalidad/ilegalidad, tiene la capacidad de mediar entre otras esferas comunicativas ${ }^{2}$. Esta mediación, desde luego, nunca es pasiva y transparente: siempre es constitutiva ${ }^{3}$ por cuanto la reformulación de la realidad en términos jurídicos involucra un ejercicio de selección entre conceptos jurídicos rivales, ejercicio cuyos márgenes de discrecionalidad son siempre amplios. Traduttore, traditore.

En otras palabras, la selección de la forma en que los tribunales presentan los hechos discutidos es en sí ya un acto que constituye realidades ${ }^{4}$. Quienes

\footnotetext{
${ }^{1}$ Doctor en Derecho, Universidad de Yale; Profesor Auxiliar, Facultad de Ciencias Jurídicas y Sociales, Universidad Austral de Chile. Correo electrónico: fernando.munoz@uach.cl.
}

2 Véase Lummann, Niklas, "Law as a Social System", Northwestern University Law Review Vol. 83, 1989, p. 136-150; esp., p. 137- 139.Para Luhmann, "uno puede concebir al derecho como un sistema social sólo si uno toma en cuenta el hecho que este sistema es un subsistema de la sociedad, y que hay también otros subsistemas". La comprensión de las interacciones a que da lugar este hecho requiere comprender que dentro de la sociedad existe diferenciación, entendida como "el establecimiento de relaciones entre el sistema y su entorno en dichos sistemas", y que "tal diferenciación es posible sólo mediante el establecimiento de una clausura autorreferencial en los sistemas que adquieren diferenciación". Sobre la base de estas premisas, los conceptos jurídicos mismos pueden ser entendidos como "una formulación de la autorreferencialidad del sistema jurídico". Los conceptos jurídicos son nada más ni nada menos que el lenguaje del derecho, el cual este redescribe el mundo que le rodea.

${ }^{3}$ En el caso del derecho constitucional norteamericano, Post ha sostenido que "la implementación de los principios constitucionales requiere poner cuidadosa atención a la relación entre derecho constitucional y formas sistemáticas de orden social". Entre estas formas de orden social Post destaca tres que a su juicio son particularmente relevantes para entender el derecho constitucional estadounidense: comunidad, administración, y democracia. Resume su tesis de la siguiente forma: "uno podría decir que el derecho crea comunidad cuando busca interpretar e implementar normas y códigos compartidos de manera autorizada; actúa administrativamente cuando organiza la vida social de manera instrumental a fin de alcanzar objetivos específicos; y promueve democracia al establecer arreglos sociales que nos remiten al significado de la autodeterminación colectiva". Post, Robert C., Constitutional Domains: Democracy, Community, Management, Harvard University Press, Cambridge, 1995, p. 1-2.

4 Esta afirmación puede resultar de difícil aceptabilidad para quien crea que nuestro conocimiento de la realidad es directo e inmediato. De ser así, toda mediación hecha por nuestro discurso sería una distorsión; y el conocimiento resultante de ella, ideología. Reconciliarnos con el carácter cognitiva y 
recuerden la sentencia del Tribunal Constitucional dictada el 2008 sobre la píldora del día después tendrán a la mano un buen ejemplo ${ }^{5}$ : allí, un asunto que pudo haber sido analizado desde la perspectiva de la autodeterminación y los derechos reproductivos de la mujer o desde el interés estatal por contar con una política de salud pública fue conceptualizado exclusivamente como un problema de derecho a la vida ${ }^{6}$. Al escoger las categorías jurídicas dentro de las cuales es subsumida una disputa de alcances colectivos los jueces tienen la capacidad de estructurar la vida social misma. Pueden, por ejemplo, decidir si un determinado ámbito de ella estará localizado en el terreno del mercado, la jurisdicción, o la democracia. Esto, que Eduardo Novoa identificara -y criticara- como el resultado de la tensión anidada en nuestro derecho entre individualismo liberal y colectivismo regulador ${ }^{7}$, obedece en cambio a un fenómeno más profundo y más permanente: la imaginación humana, que puede encontrar una y otra vez nuevas formas de concebir las mismas realidades. Tales son las posibilidades que se presentan al órgano jurisdiccional al momento de resolver casos comoel confrontado por la Corte de Apelaciones de Santiago en el recurso de protección en comento, Agrupación Nacional de Empleados Fiscales y otro con Servicio de Impuestos Internos, fallado el 16 de septiembre de 2011.

\section{El CONFLICTO: LA ATíPICA PERO FRECUENTE PARALIZACIÓN DE ACTIVIDADES DEL SECTOR PÚBLICO}

Durante noviembre de 2010 un grupo de trabajadores paralizaron sus actividades debido a su disconformidad con el reajuste salarial que les fuera ofrecido por su empleador. Enfrentado con algo que percibió como una vulneración a las normas que rigen esta relación laboral, el empleador en cuestión resolvió descontar del salario de los trabajadores en cuestión el tiempo no trabajado.

culturalmente mediado de nuestro conocimiento nos lleva a reformular el concepto de ideología para describir a aquel conocimiento que niega su propia contingencia y falibilidad, que afirma su total plenitud y carencia de fisuras. Sobre las mediaciones de nuestra comprensión de los hechos y su impacto en nuestras concepciones jurídicas, véase KaHAN, Dan, "The Supreme Court 2010 Term. Foreword: Neutral Principles, Motivated Cognition, and some problems for Constitutional Law", Harvard Law Review Vol. 125, 2011 (en imprenta). Sobre el concepto de ideología, véase LACLAU, Ernesto, "Muerte y resurrección de la teoría de la ideología", en Misticismo, retórica y política, Fondo de Cultura Económica, 2002, p. 9-55.

${ }^{5}$ Sentencia del Tribunal Constitucional en Causa Rol № 740 , acoge requerimiento de inconstitucionalidad contra Decreto Supremo Reglamentario № 48 que aprueba “Normas Nacionales sobre Regulación de la Fertilidad", 18 de abril de 2008.

6 Para una crítica a los silencios de esta sentencia, véase Bordalí, Andrés; ZúÑIGA, Yanira, "Análisis del fallo del Tribunal Constitucional sobre la píldora del día después", Anuario de Derechos Humanos No 5, p. 177.

7 NovoA, Eduardo, Obras Escogidas: Una Crítica al Derecho Tradicional, Santiago, Centro de Estudios Políticos Latinoamericanos Simón Bolívar, 1993, p. 94. 
Esta problemática podría haber sido de fácil resolución jurídica si no fuera por un importante hecho: se trataba de funcionarios públicos. En este caso, más específicamente, del Servicio de Impuestos Internos.

El contexto de dicha paralización fue lacompleja negociación llevada a cabo en aquella época entre el Ejecutivo, el Congreso y los representantes de los funcionarios públicos en torno al monto del reajuste salarial de estos últimos. Mientras el Ejecutivo ofrecía un $3,7 \%{ }^{8}$ los trabajadores exigían y se movilizaban por un 5,0\%, a la vez que el Congreso servía de foro para la discusión. Finalmente se llegó a una votación en que, polémica ausencia del presidente de uno de los partidos opositores mediante ${ }^{9}$, primó la (segunda) propuesta del Ejecutivo de aumentar los salarios en un $4,2 \%{ }^{10}$.

Sin embargo, los problemas no terminaron ahí. La intensa movilización organizada por los dirigentes de los empleados fiscales significó la paralización de las actividades de diversos servicios públicos; entre ellos, el Servicio de Impuestos Internos (SII). Ante este hecho la dirección de esta institución procedió a efectuar lo que, en su entendimiento, legalmentecorrespondía hacer: deducir de las remuneraciones de los funcionarios el "tiempo durante el cual no se hubiere efectivamente trabajado", al decir del artículo 72 del Estatuto Administrativo. Listados de funcionarios ausentes, confeccionados con fecha 30 de noviembre por los jefes inmediatos de los trabajadores y visados por los Directores Regionales y el Director de Grandes Contribuyentes, fueron enviados al Director Nacional a fin de efectuar las deducciones correspondientes. El 14 de enero dichos listados fueron nuevamente revisados a fin de corregir errores, los cuales según el SII no excedían del diez por ciento del total de los casos.

Una medida de este tipo, en circunstancias distintas, habría sido enfrentada por empleadores y trabajadores desde la experticia entregada por la cotidianeidad del conflicto laboral y desde las categorías ius laborales surgidas de allí. La diferencia con el caso de los funcionarios públicos, ahora bien, no se localiza en el mundo extensional de los hechos físicos, donde el conflicto laboral es tan frecuente en el sector público como en el privado. La diferencia se ubica en el "cielo de los conceptos jurídicos", según la irónica

\footnotetext{
${ }^{8}$ Véase Mensaje de S.E. el Presidente de la República con el que se inicia un proyecto de ley que otorga un reajuste de remuneraciones a los trabajadores del sector público, concede aguinaldos que señala, y concede otros beneficios que indica, Boletín 7330-07, ingresado el 30 de noviembre de 2010.

9 "Ausencia del diputado Andrade durante votación de reajuste público abre polémica en la oposición". En: http://www.elmostrador.cl/noticias/pais/2010/12/16/ausencia-del-diputado-andrade-durantevotacion-de-reajuste-publico-abre-polemica-en-la-oposicion/ [visitado el 21/09/2011].

${ }^{10}$ Véase Ley № 20.486, Otorga reajuste de remuneraciones a los trabajadores del sector público, concede aguinaldos y otros beneficios que indica, promulgada el 16 de diciembre de 2010 y publicada el 17 de diciembre de 2010.
} 
expresión de Von Ihering ${ }^{11}$. En otras palabras, la dificultad estriba en la atipicidad del conflicto laboral fiscal. Pese a la "existencia indesmentible" de las movilizaciones o paralizaciones de los funcionarios del Estado, al decir de la sentencia en comento, nuestro derecho no conceptualiza explícitamente el conflicto laboral fiscal. Incluso más, en la interpretación prevaleciente, que es ciertamente la que guió el actuar del SII, el conflicto laboral fiscal no es atípico sino ilegal. Mal que mal, la propia Constitución dice textualmente que los funcionarios del Estado no podrán declararse en huelga; precepto reiterado -como bien se encargó el SII de hacerlo ver en su Informe evacuado en el recurso de protección en cuestión-por el Código del Trabajo, la Ley de Asociaciones de Funcionarios de la Administración del Estado, la Ley sobre Seguridad Interior del Estado, y el Estatuto Administrativo. Con este respaldo, es comprensible que el SII sostuviera que "este Servicio se ha ajustado con su actuar a la legislación vigente, la cual, mientras no sea modificada, deberá ser aplicada como en derecho corresponde y no como el recurrente, a través de su particular interpretación, le gustaría que fuese $\mathrm{e}^{\prime 12}$.

Ante esta avalancha de textos legales, sólo es posible reivindicar la idea de que el conflicto laboral fiscal no es contrario a derecho -ilegal- sino que tan sólo no está conceptualizado directamente -atípico- invocando la existencia del Convenio 151 de la Organización Internacional del Trabajo (OIT).A la luz del Artículo 5 de la Constitución, dicho Convenio puede adquirir el valor de fuente de limitaciones a la aplicación de las normas procedimentalmente válidas dictadas por los organismos constitucionalmente competentes; es decir, de limitación al "ejercicio de la soberanía", al decir de la propia Constitución. Los ordenamientos jurídicos, mal que mal, se construyen sobre la base de principios fundamentales-"conceptos de moralidad política"13 o fines últimos- que en ocasiones pueden llevar a los tribunales a desobedecer textos expresos, incluso cuando dichos textos estén en la propia Constitución. Ya lo hizo nuestro Tribunal Constitucional en su sentencia de mayor relevancia histórica desde el punto de vista del impacto en el proceso político ${ }^{14}$. Este tipo de casos establecen un puente entre el

\footnotetext{
${ }^{11}$ Von IHERING, Rudolf, "In theHeavenfor Legal Concepts: A Fantasy", Temple LawQuarterly Vol. 58, 1985, p. 799-842.

${ }^{12}$ Subdirector Jurídico del Servicio de Impuestos Internos, Informe presentado en Recurso de Protección Rol No 544-2011, 2 de Marzo de 2011, p. 6.

${ }^{13}$ Dworkin, Ronald, Freedom'slaw: the moral reading of the American constitution, Oxford UniversityPress, Oxford, 1999.

14 Sentencia del Tribunal Constitucional en Causa Rol № 33, declara inconstitucional proyecto de Ley Orgánica Constitucional sobre Tribunal Calificador de Elecciones, 24 de septiembre de 1985. En dicha sentencia, el Tribunal expresa que la Constitución "es un todo orgánico y el sentido de sus normas debe ser determinado de manera tal que exista entre ellas la debida correspondencia y
} 
razonamiento jurídico y el razonamiento moral que nos remiten a su común condición de formas del razonamiento práctico, invitándonos a ver el obsoleto problema sobre la distinción o conexión conceptual entre moral y derecho como un problema sobre las razones para $\operatorname{actuar}^{15}$ y el rol que ellas juegan en la justificación de las decisiones ${ }^{16}$. En la comprensión de esta dimensión y de las estrategias utilizadas por los operadores jurídicos para navegar por ella ningún método de observación puede ser desechado. Incluso pequeños detalles gramaticales como los énfasis tipográficos de distintos textos pueden revelar cómo los operadores jurídicos estructuran sus argumentaciones sopesando de una u otra manera los componentes de los materiales jurídicos. Así, mientras que el SII transcribe una cita doctrinal enfatizando la ilegalidad del conflicto laboral fiscal ("en el sector público se producen numerosas negociaciones informales, se firman acuerdos y protocolos que a veces son verdaderos contratos colectivos y se ha vuelto común la realización de huelgas y paralizaciones ilegales a fin de presionar a la autoridad respecto de una determinada pretensión" ${ }^{\prime 17}$ ), la Corte de Apelaciones transcribe la misma cita enfatizando, en cambio,la atipicidad del conflicto laboral fiscal "en el sector público se producen numerosas negociaciones informales, se firman acuerdos y protocolos que a veces son verdaderos contratos colectivos y se ha vuelto común la realización de huelgas y paralizaciones ilegales a fin

armonía, excluyéndose cualquiera interpretación que conduzca a anular o a privar de eficacia algún precepto de ella" (Considerando 19º). Esta afirmación no puede sino ser calificada de deliberadamente engañosa cuando lo que se está haciendo es, precisamente, 'privar de eficacia' ciertos preceptos de la propia Constitución. En dicha sentencia el Tribunal debió formular una teoría explícita y substantiva de lo que estaba haciendo: esto es, debió justificar la priorización que hizo del bien constitucional consistente en lalegitimidad democrática del sistema político constitucionalmente proclamada en los Artículos $4^{\circ}$ y 18 de la Constitución por sobre el bien constitucional consistente en el respeto a la distribución de competencias legislativas constitucionalmente establecida, en aquel entonces, en la Disposición Transitoria 18 a . Esta última, en efecto, es la disposición que el Tribunal 'privó de eficacia', no el Artículo 84 ni tampoco la Disposición Transitoria 11 a , ya que estas se limitaban a determinar que sería la "ley respectiva" la que determinaría la fecha de instalación del Tribunal Calificador de Elecciones. La Junta de Gobierno, que según la Disposición Transitoria $18^{a}$ ejercería el Poder Legislativo durante el período presidencial iniciado en marzo de 1980, era entonces la autoridad a la que el ordenamiento jurídico le entregaba la potestad de determinar discrecionalmente cuándo entraría en funcionamiento el Tribunal Calificador de Elecciones. En nombre de un valor o bien más apremiante, el robustecer la legitimidad democrática de un sistema político surgido de una dictadura, el Tribunal Constitucional estimó justificado desconocer dicha distribución de competencias legislativas y actuar ya no como legislador negativo sino, derechamente, como legislador a secas. Que eso deba ocurrir constantemente, desde luego, no se sigue de ello; la vida de la República no está en juego todos los días.

15 Raz, Joseph, Practical Reason and Norms, Oxford University Press, Oxford, 1975.

${ }^{16}$ MacCormick, Neil, Rhetoric and the Rule of Law: A Theory of Legal Reasoning, Oxford UniversityPress, Oxford, 2009.

${ }^{17}$ Informe, cit. nota n. 11, p. 6. 
de presionar a la autoridad respecto de una determinada pretensión"18).Si para unos la frecuencia de estos actos constituye una violación reiterada del derecho, para los otros representa una realidad social de la cual el órgano jurisdiccional ha de hacerse cargo. Estos distintos énfasis, en efecto, dan pie a construcciones jurisprudenciales opuestas: la del SII y la de la Corte, la cual invoca el Convenio 151 de la OIT, calificándole de "ciertamente proclive a la protección de los derechos sindicales de los funcionarios públicos, entre los cuales debe entenderse ínsito el derecho a negociar colectivamente"19. Mediante estos expedientes argumentativos, la Corte abre las puertas a la laboralización de una relación antes mediada por la condición administrativa de los sujetos de la relación, invocando con ello los principios de justicia que rigen las relaciones en el mercado del trabajo. Si los empleados fiscales son considerados como trabajadores, "debe entenderse ínsito el derecho a negociar colectivamente" ${ }^{20}$.

\section{LA SOLUCIÓN ENCONTRADA: EL DEBIDO PROCESO}

Esto, sin embargo, no satisface completamente la pretensión de los empleados fiscales.El reclamo de éstos, mal que mal, girabano en torno al reconocimiento de su derecho a negociar colectivamente -el cual han ejercido contra legem- sino al descuento de que fueran objeto. Esto, que en el contexto de las prácticas construidas en torno al conflicto laboral del sector privado podría haberse resuelto mediante un bono por término de conflicto ${ }^{21}$, se transforma en un problema allí donde el principio de legalidad del gasto público impide la discrecionalidad con que los empleadores particulares pueden disponer de sus recursos.

La situación concreta que suscita este recurso se presta para recurrir a una solución intermedia: la anulación del descuento en nombre del debido pro-

\footnotetext{
${ }^{18}$ Sentencia de la Corte de Apelaciones de Santiago en Causa Rol № 544-2011, Agrupación Nacional de Empleados Fiscales y otro con Servicio de Impuestos Internos, 16 de septiembre de 2011, Considerando $5^{\circ}$.

${ }^{19}$ Sentencia, cit. nota n. 18, Considerando $5^{\circ}$. El Convenio 151, cabe observar, es bastante explícito en sus artículos $7^{\circ}$ y $8^{\circ}$ en calificar como un bien o valor la "utilización de procedimientos de negociación entre las autoridades públicas competentes y las organizaciones de empleados públicos acerca de las condiciones de empleo".

${ }^{20}$ Dando cuenta del significado de la dirección interpretativa tomada por la Corte, el Presidente de la Asociación de Fiscalizadores de Impuestos Internos de Chile Juan Apablaza "calificó como 'histórico' el hecho de que el tribunal de alzada refrendara 'que nosotros tenemos negociación colectiva y derecho a huelga a partir del Convenio 151 de la OIT'”. En: http://www.cooperativa.cl/corte-de-apelacionesordeno-al-sii-devolver-descuentos-a-funcionarios-que-estuvieron-en-paro/prontus_nots/2011-0920/123531.html [visitado el 21/09/2011].

${ }^{21}$ Agradezco a Pablo Arellano haberme aclarado este punto.
} 
ceso constitucional. El hecho, que los recurrentes califican de "innumerables errores e inconsistencias en la aplicación y determinación de los descuentos" y que los recurridos reconocen únicamente como "errores puntuales", es que hubo descuentos calculados erróneamente. Pero la Corte no opta, como podría haberlo hecho, por instruir que se revisen nueva y más cuidadosamente los descuentos realizados. Opta por una alternativa más radical: privar de toda veracidad epistémica la actuación misma del SII, sosteniendo que en el contexto de "masividad" de la paralización de actividades de autos "no puede resultar convincente ni verosímil el simple control de cada jefe de sección o departamento'. El 'holding' de esta sentencia, su medular aporte doctrinal en materia de derecho administrativo, consiste en afirmar que "el procedimiento de descuentos, reglamentado en el citado artículo 72 del Estatuto Administrativo, pensado y articulado evidentemente para una situación de apacible y normal desarrollo de los servicios, no puede resultar debidamente operativo en trance de paralización o movilización más o menos generalizada"22.

Esta conclusión, que se proyecta en la interpretación del Estatuto Administrativo, tiene a su vez una consecuencia importante en el terreno propiamente jurisdiccional. Esto, por cuanto uno de los principios fundamentales en torno al cual gira esta dimensión es el valor epistémico del proceso, su función como mecanismo de construcción de conocimiento. Cuando la Corte afirma que el actuar del SII "no puede resultar convincente ni verosímil" le priva de toda validez jurisdiccional. Ahora bien, como es evidente, lo que está en juego no es la 'cláusula constitucional' del tribunal natural ("Nadie podrá ser juzgado por comisiones especiales, sino por el tribunal que señalare la ley y que se hallare establecido por ésta con anterioridad a la perpetración del hecho") sino la del debido proceso ("Toda sentencia de un órgano que ejerza jurisdicción debe fundarse en un proceso previo legalmente tramitado. Corresponderá al legislador establecer siempre las garantías de un procedimiento y una investigación racionales y justos"). El problema, dirá horrorizado un textualista, es que el artículo 20 de la Constitución ofrece su protección a quien se vea privado, perturbado, o amenazado en el ejercicio de su derecho a ser juzgado por el tribunal establecido con anterioridad a la perpetración del hecho que le señalare la ley; mas no ofrece dicho auxilio a quien desee velar por que el legislador establezca siempre las garantías de un procedimiento y una investigación racionales y justos. ¿Estamos entonces ante la tan temida creación judicial de derechos? Quizás.Y si bien esto es más normal de lo que quisiéramos creer-ya bien decía Schmitt, en un arranque de 'legal realism', que en la

${ }^{22}$ Sentencia, cit. nota n. 17, Considerando $6^{\circ}$. 
realidad de la vida jurídica lo que importa es quién decide ${ }^{23}$-, es cierto que en una cultura textualista y poco teleológica como la nuestra esta movida de la Corte ofrece un suelo poco sólido para las pretensiones de los trabajadores.

Por añadidura, a efectos de los intereses de los trabajadores fiscales hay otrasdos conclusiones alarmantes que surgen de la ubicación de la discusión en el terreno de la jurisdiccion. En primer lugar, ¿estaba la Corte atada de manos por la fragilidad epistémica del actuar del SII?¿Estaba obligada irremediablemente a resolver que la evidencia surgida del procedimiento del SII no era "convincente ni verosímil"? Desde luego que no. El proceso, al decir de Taruffo, "al no ser una empresa científica o filosófica, no necesita de verdades absolutas, pudiéndose contentar con mucho menos, es decir, con verdades relativas de distintos tipos, pero suficientes para ofrecer una base razonablemente fundada a la decisión" ${ }^{\prime 24}$. Una vez más, la determinación de qué constituye un conocimiento suficiente o razonable ofrece sutiles espacios de discrecionalidad para el tribunal, en virtud de los cuales -e invocando criterios tales como la eficiencia o la efectividad de los actos de la administración- la Corte bien podría haber aceptado la validez de los hechos. En segundo lugar, ¿qué pasará si el SII u otro servicio establece en el futuro procedimientos e investigaciones racionales y justos para determinar el "tiempo durante el cual no se hubiere efectivamente trabajado" durante las movilizaciones suscitadas en el futuro en el marco de sus conflictos laborales? ¿Podrá seguir la Corte ordenando reintegros? Parece evidente que no.

Estas preguntas revelan las limitaciones inherentes a la jurisprudencia jurisdiccional en materia del artículo 72 del Estatuto Administrativo: de ser satisfechas las exigencias de racionalidad y justicia en el proceso de determinación de las deducciones, el Estado podrá descontarle a los trabajadores movilizados las horas no trabajadas, apagando efectivamente las posibilidades de que los trabajadores fiscales utilicen todo el repertorio conflictual caracterizado por el"pleno desarrollo y utilización de procedimientos de negociación" al decir del Convenio 151.

\section{Un CAMINO ALteRNATIVO: LAS LIBERTADES PÚBlicAS}

Ni el mercado ni la jurisdicción, en conclusión, son capaces de ofrecerle a los trabajadores las protecciones que hagan efectiva su libertad sindical. ¿Habrá otro terreno que garantice mayor solidez a su marcha?

\footnotetext{
${ }^{23}$ SChmiтt,Carl, Political Theology. Four chapter son the concept of sovereignty, The University of Chicago Press, Chicago, 1985, p.34.

${ }^{24}$ TAruffo, Michele, La prueba de los hechos, 2a Edición Trotta, Madrid, 2005, p. 177.
} 
El propio Convenio 151 nos sugiere un camino alternativo, distinto a los explorados por la Corte en la sentencia en comento: la democracia y sus concomitantes libertades públicas. La clave está en el artículo 9 de dicho instrumento, el cual dispone que los empleados públicos"gozarán de los derechos civiles y políticos esenciales para el ejercicio normal de la libertad sindical, a reserva solamente de las obligaciones que se deriven de su condición y de la naturaleza de sus funciones".

¿Qué derechos civiles y políticos son esenciales para el ejercicio normal de la libertad sindical? Sin duda, el derecho de asociarse sin permiso previo; el derecho a reunirse pacíficamente sin permiso previo; y la libertad de emitir opinión. Todas estas libertades públicas, a diferencia del derecho al juez natural, están protegidas por el recurso de protección. Ellas clarifican y robustecen normativamente el atípico conflicto laboral fiscal. Desde su perspectiva, las movilizaciones no son ilegales; constituyen el ejercicio de derechos constitucionalmente establecidos y garantizados en el contexto del conflicto surgido del ejercicio normal de la libertad sindical. Llevada esta tesis a su conclusión lógica, un tribunal debería resolver que en casos de conflicto laboral fiscal, el descuento establecido por el artículo 72 del Estatuto Administrativo no puede ser aplicado no porque sea de difícil determinación -que puede dejar de serlo- sino porque constituiría una amenaza, al decir del artículo 20 de la Constitución, en el legítimo ejercicio de los derechos ya mencionados. Razonando de esta manera un tribunal podría reimaginar nuestra Constitución, tan escuálida en la protección de los intereses y derechos sociales y tan criticada por ello una y otra vez, utilizando nada más que textos jurídicos vigentes y aplicables.

Se podría objetar que esto dejaría a los empleados fiscales en mejor posición que los trabajadores del sector privado, al ofrecerle a éstos un tipo de protección a todo evento contra deducciones no disponible para aquellos. Esta objeción, sin embargo, olvidaría que los trabajadores cuentan con la posibilidad de recibir bonos por término de conflicto, posibilidad que debido a las constricciones del principio de legalidad del gasto público no está al alcance del sector público.

En conclusión, los tribunales tienen la posibilidad efectiva de estructurar las relaciones sociales sometidas a su consideración bajo diferentes prismas o lógicas. Y si bien a nivel 'macro' -esto es, en el plano de nuestra institucionalidad política- las debilidades y deficiencias de nuestra democracia son muchas, a nivel 'micro' -esto es, en el plano de las relaciones interpersonales- las posibilidades y potencialidades de la democracia, estructurada por las libertades de asociación, reunión y opinión, son también múltiples. Queda por ver si nuestros tribunales serán capaces de sacarles todo el partido que corresponde. 
IV. Sentencia de la corte de apelaciones de santiago en Causa rol No $544-$

2011, AGRUPACIÓN NACIONAL DE EMPLEADOS FISCALES Y OTRO CON SERVICIO DE IMPUESTOS INTERNOS, 16 DE SEPTIEMBRE DE 2011

Corte de Apelaciones de Santiago

Santiago, dieciséis de septiembre de dos mil once .

Vistos y teniendo presente:

$\left.1^{\circ}\right)$ Que la Agrupación Nacional de Empleados Fiscales (ANEF), y la Asociación Nacional de Empleados Fiscalizadores de Impuestos Internos de Chile (AFIICH) han deducido, a favor de todos los funcionarios incluidos en la nómina que adjuntan, recurso de protección en contra del Servicio de Impuestos Internos de Chile (SII), por el acto que dicen ilegal y arbitrario consistente en la privación total o parcial de sus remuneraciones, fundada en supuestas inasistencias a su trabajo durante los días que duró la paralización de actividades convocada por ANEF y AFIICH, entre los meses de noviembre y diciembre de 2010, en el marco del proceso de negociación colectiva que desde hace veinte años se viene realizando entre la denominada Mesa del Sector Público y el gobierno de turno.

Expresan que se trata de descuentos masivos, sin discriminación ni prolijidad, incluyendo funcionarios ausentes por causas justificadas como licencias o feriados y otras, y sin considerar el tiempo realmente no trabajado, al descontar genéricamente por todos los días de paro, a pesar de la asistencia y registro de asistencia de los funcionarios afectados, y a pesar de haberse cumplido a lo menos parcialmente las funciones, por parte de muchos que no acataron la paralización, o lo hicieron en forma parcial.

Sostienen haberse vulnerado con dicho acto la garantías constitucionales de los numerales 3 inciso cuarto y 24 del artículo 19 de la Constitución Política del Estado: se ha violentado la igual protección de la ley en el ejercicio de los derechos de los recurrentes, en cuanto no han sido juzgados ni sancionados en un debido proceso por tribunal competente establecido con anterioridad, sino arbitrariamente por la dirección superior de la institución recurrida, constituida de hecho en comisión especial al efecto. Y violentado también su derecho de propiedad en lo que atañe a su legítimo derecho a percibir sus remuneraciones.

Explican que sorpresivamente el día 19 de enero de 2011, luego de no haberse publicado las liquidaciones en el sistema informático el día 17, como se venía haciendo conforme a un calendario oficial, se les informó la decisión de descontar en el día mismo del pago de las remuneraciones, y que tanto la omisión de las publicaciones como los referidos descuentos habían obedecido a instrucciones del Ministro de Hacienda al Director del SII recurrido.

$2^{\circ}$ ) Que explicitando sus asertos, los recurrentes afirman: A) Que no ha existido información fidedigna justificativa o legitimadora de los descuentos, 
tanto respecto del número de días no trabajados, cuanto del número de funcionarios que habrían acatado el paro y participado del mismo, como tampoco acerca de si la paralización habría abarcado todos los días del período de movilización y el total de las jornadas involucradas, o sólo parte de los mismos. B) Que no todos los funcionarios afectados participaron del paro, habiendo sido variable el número concreto de días no trabajados total o parcialmente. C) Que no es efectivo que se trate de "inasistencias", porque durante esos días todos los funcionarios sí asistieron, registrando su presencia, sólo paralizando o interrumpiendo total o parcialmente la efectiva prestación de sus servicios. D) Que todo lo anterior ha redundado en innumerables errores e inconsistencias en la aplicación y determinación de los descuentos, haciéndoseles extensivos a funcionarios ausentes por licencias, feriados u otros motivos por demás justificados, según listados que rolan de fojas 61 a 63 .

$3^{\circ}$ ) Que en virtud de tales antecedentes y razones, los recurrentes solicitan se acoja su recurso, dejando sin efecto el acto impugnado, ordenando la restitución de los dineros arbitraria e ilegalmente descontados, y declarando que no procede descuento alguno en tanto no se determine en forma fehaciente a través de una investigación sumaria, el tiempo efectivamente no trabajado por cada funcionario.

$4^{\circ}$ ) Que en su informe de fojas 89 y siguientes, la Dirección recurrida ha solicitado el rechazo de la acción tutelar de protección, en razón de las siguientes argumentaciones: A) Que la negociación colectiva y movilización llevada a cabo por los recurrentes escapa de toda legalidad: A1) Porque el Código del Trabajo en su artículo $1^{\circ}$ inciso $2^{\circ}$ dispone la exclusión de sus normas a su respecto; A2) Porque dicho Código contempla la huelga sólo como un derecho dentro el procedimiento reglado de negociación colectiva del sector privado; A3) Porque el precepto 19 numeral 16 de la Constitución Política del Estado prohíbe expresamente la huelga de los funcionarios del Estado; A4) Porque la Ley 19.296 sobre asociaciones de funcionarios de la administración del Estado, impide a su respecto la negociación colectiva y la huelga, los paros y las movilizaciones; A5) Porque la Ley 12.927 sobre seguridad interior del Estado sanciona penalmente en su artículo 11 a los responsable de toda interrupción o suspensión colectiva, paro o huelga de los servicios públicos o de utilidad pública; A6) Porque la norma del artículo 84 letra i) del Estatuto Administrativo, Ley 18.834, prohíbe expresamente dirigir, promover o participar en huelgas, interrupciones o paralizaciones totales o parciales perturbadoras del normal funcionamiento de los órganos de administración del Estado; A7) Porque el artículo 54 de la ley de bases generales de administración del Estado, $N^{\circ} 18.575$, establece el principio obligatorio de probidad administrativa para los funcionarios de la administración del Estado; A8) Porque el Convenio No 151 de la Organización Internacional del Trabajo (OIT), sobre relaciones de trabajo 
en la administración pública, no contempla la huelga, paros ni movilizaciones como derechos de los funcionarios públicos, sin que tampoco el Servicio haya incurrido en ninguno de los actos persecutorios o discriminatorios a que alude el artículo $4^{\circ}$ ) letra b) de dicha convención internacional. B) Porque para la determinación de los descuentos se habría aplicado un "justo y racional procedimiento", atenido estrictamente a la normativa del artículo 72 del Estatuto Administrativo, no obstante lo cual se reconocen errores en el procesamiento de la información, causantes de "inconsistencias puntuales" que -se dice- no habrían superado el diez por ciento de los descuentos efectuados. C) Que con anterioridad a la presentación del recurso de autos, "a cada funcionario ya se le habría restituido como corresponde sus remuneraciones" (si bien en estrados adujo haber terminado de hacerlo en "Mayo 2011").

$5^{\circ}$ ) Que para la debida apreciación del contexto fáctico legal atendible en la especie, resulta necesario en primer lugar tener presente que, como lo señala el tratadista Sergio Gamonal ("Negociación colectiva en el sector público y el Convenio $N^{\circ} 151$ de la OIT"), citado por el propio Servicio recurrido, "en el sector público se producen numerosas negociaciones informales, se firman acuerdos y protocolos que a veces son verdaderos contratos colectivos y se ha vuelto común la realización de huelgas y paralizaciones ilegales a fin de presionar a la autoridad respecto de una determinada pretensión".

Se trata, al decir del autor citado, de "numerosas huelgas informales" en el sector públicoy, según es público y notorio, movilizaciones o paralizaciones, cuya existencia indesmentible ha venido a caracterizar y aún condicionar-desde hace ya tiempo- las relaciones laborales en los servicios públicos, sin que se haya necesariamente desvirtuado ni la función pública ni su debida continuidad, merced a la reflexiva prudencia de acuerdos y consensos entre la autoridad y los funcionarios involucrados, al cabo de las referidas movilizaciones.

Ello resulta concordante con la normativa del citado Convenio 151 de la OIT, ciertamente proclive a la protección de los derechos sindicales de los funcionarios públicos, entre los cuales debe entenderse ínsito el derecho a negociar colectivamente.

$\left.6^{\circ}\right)$ Que también resulta necesario considerar que el procedimiento de descuentos, reglamentado en el citado artículo 72 del Estatuto Administrativo, pensado y articulado evidentemente para una situación de apacible y normal desarrollo de los servicios, no puede resultar debidamente operativo en trance de paralización o movilización más o menos generalizada, cuyo es el caso de autos, en cuanto: A) Se trata de paralización de actividades, con asistencia del personal involucrado, lo que hace inviable el mero examen de los controles de asistencia. B) Se trata, pues, de que la totalidad o casi totalidad de los funcionarios de las diversas dependencias del servicio, se encuentran presentes y manifestando en el interior y en el frontis del local del Servicio, pero no nece- 
saria y precisamente todo el tiempo en el lugar o dependencia precisa de su desempeño habitual, sino en continuo movimiento y circulación, circunstancias todas impedientes de un adecuado control de presenciani de actividad, durante toda la jornada laboral, por parte de cada jefatura. C) Atendida la masividad de la movilización, se ha imposibilitado, de hecho, la prestación de los servicios de aquellos funcionarios no adherentes a la misma, respecto de los cuales su inasistencia o inactividad debe entenderse debida a caso fortuito o fuerza mayor, no susceptible de fidedigna comprobación. D) En razón de la dicha masividad (el recurrido ha reconocido en estrados que se trató de 2.074 descuentos, correspondientes aproximadamente al 50\% del total de funcionarios del Servicio), no puede resultar convincente ni verosímil el simple control de cada jefe de sección o departamento, dado el alto número de funcionarios movilizados y la complejidad de los cómputos pertinentes.

$7^{\circ}$ ) Que las circunstancias antedichas, a juicio de estos sentenciadores, deslegitiman el control y cómputo invocados por el recurrido por la deficiencia de su resultado, en tanto ha desembocado en la errónea personalización y cuantificación de los descuentos, reconocida por el Servicio para a lo menos un diez por ciento del total de funcionarios involucrados, especialmente en cuanto además: A) No se ha acreditado en autos por el Servicio recurrido haberse efectivamente contado con el "requerimiento escrito del jefe inmediato" de todos los funcionarios sancionados con los descuentos. B) No se han explicitado debidamente los procedimientos de acreditación de las respectivas paralizaciones diarias, totales o parciales, del personal involucrado. C) No se ha acreditado a cabalidad la efectividad de las restituciones que por descuentos erróneos ha invocado el servicio recurrido, según se ha expresado en la letra C) del Considerando Cuarto del presente fallo, y en cuanto, además, los documentos acompañados de fojas 151 a 153 resultan insuficientes al efecto.

A mayor abundamiento, aun cuando pudiere entenderse enmendados dichos errores en la medida de la restitución referida, ello no puede legitimar el erróneo procedimiento empleado, especialmente en cuanto a la carencia de fidedigna determinación de los tiempos no trabajados por el resto de los recurrentes.

$\left.8^{\circ}\right)$ Que como se ha declarado en diversos dictámenes de la Contraloría General de la República, tratándose de la aplicación de sanciones, debiendo ser necesariamente éstas de Derecho estricto, por mandato constitucional del invocado artículo $19 \mathrm{~N}^{\circ} 3^{\circ}$ del Texto Fundamental, debe respetarse la garantía de "un procedimiento y una investigación racionales y justos", lo que a juicio de estos sentenciadores no ha podido ocurrir en el caso sub lite, dadas las falencias de control y procedimentales anteriormente reseñadas, así como la inobservancia de principios básicos como los de transparencia y contradictoriedad establecidos perentoriamente por el legislador de la Ley 19.880, sobre bases de los procedimientos administrativos de los órganos del Estado. 
$9^{\circ}$ ) Que a propósito del imperativo constitucional de legalidad o legitimidad de los actos de autoridad, sabida es la distinción entre legalidad o legitimidad de origen, relativa a la existencia y reconocimiento de la potestad jerárquica del jefe del servicio --que en la especie no podría por cierto ser controvertida-y la legalidad de ejercicio (sí puesta en tela de juicio por la acción tutelar ejercida en estos autos), que supone la debida concurrencia del presupuesto fáctico legitimador, sin la cual el acto cuestionado deviene en arbitrariedad.

En la especie, habida consideración de las graves falencias de cómputo y de fiscalización antes referidas, no ha podido determinarse fehacientemente cuáles debieron ser las cantidades legítimamente descontables a cuáles recurrentes, especialmente a la luz de los yerros reconocidos por el propio servicio recurrido, resultando así ineludible la conclusión de la dicha arbitrariedad, frente a la dubitable concurrencia del presupuesto fáctico de no prestación efectiva de los servicios por los recurrentes.

$10^{\circ}$ ) Que en virtud de todo lo razonado precedentemente, y apreciados los antecedentes según las reglas de la sana crítica -en especial de lógica y de experiencia- estos sentenciadores estiman haberse conculcado en la especie las garantías constitucionales invocadas por los recurrentes.

Por estas consideraciones, normas legales citadas y artículos 19 y 20 de la Constitución Política del Estado, y normas del Auto Acordado sobre Tramitación del Recurso de Protección, se acoge el recurso deducido a fojas 37, sin costas, ordenándose al Servicio de Impuestos Internos la restitución, dentro del plazo de treinta días, de todas las sumas descontadas de sus remuneraciones a los recurrentes enlistados de fojas 4 a 36, correspondientes a los meses de Noviembre y Diciembre de 2010, por inasistencias o no prestación efectiva de sus servicios. Y declarándose que no procede efectuar descuento alguno por los meses señalados, por los rubros referidos, en tanto no se determinen fehacientemente, a lo menos a través de condigna investigación sumaria, los tiempos no trabajados por los recurrentes en la época señalada.

Redacción del Abogado Integrante señor Antonio Barra Rojas.

Regístrese, comuníquese y archívese.

No Protección 544 - 2011.

Pronunciada por la Séptima Sala de esta Corte de Apelaciones de Santiago, presidida por el Ministro señor Mario Rojas González e integrada por la Ministra señora Pilar Aguayo Pino y por el Abogado Integrante señor Antonio Barra Rojas. No firma la Ministra señora Aguayo, no obstante haber concurrido a la vista y acuerdo del fallo, por encontrarse ausente. 